Research Article

\title{
Iridium-Based Dual-Functional Nanoparticles for Far- Red Imaging and Photodynamic Therapy
}

\author{
Lanying Guo ${ }^{1,2}$, Hongshang Peng ${ }^{1}$, Ruiying Shen ${ }^{2}$, Jiantao Ping ${ }^{1,2}$, Fangtian You ${ }^{2}$, Yiquan Wang ${ }^{1}$, \\ Min Song ${ }^{1}$, Qu Zhen ${ }^{1}$ \\ ${ }^{1}$ School of Science, Minzu University of China, Beijing 100081, China. \\ ${ }^{2}$ Key Laboratory of Luminescence and Optical Information, Ministry of Education, Institute of Optoelectronic Technology, Beijing \\ Jiaotong University, Beijing 100044, China.
}

$\square$ Corresponding author. E-mail: hshpeng@bjtu.edu.cn

Received: Nov. 3, 2016; Accepted: Dec. 27, 2016; Published: Jan. 19, 2017.

Citation: Lanying Guo, Hongshang Peng, Ruiying Shen, Jiantao Ping, Fangtian You, Yiquan Wang, Min Song, and Qu Zhen, Iridium-Based DualFunctional Nanoparticles for Far-Red Imaging and Photodynamic Therapy. Nano Biomed. Eng., 2017, 9(I): I-8.

DOI: 10.5101/nbe.v9i1.p1-8.

\begin{abstract}
Phosphorescent iridium complexes ranged from far-red to NIR have attracted great attention as oxygen probes or photosensitizers recently. In this work, a far-red phosphorescent iridium complex ((DPQ) $)_{2} \operatorname{Ir}($ acac $)$ ) was adopted to prepare biocompatible nanoparticles (Ir-NPs) for both phosphorescence imaging and photodynamic therapy of living cells. The iridium complex was highly sensitive to oxygen in organic solvent, but became less insensitive after being incorporated into NPs, though the particle matrix was highly permeable to oxygen. Moreover, the Ir-NPs exhibited a fast rate of singlet oxygen generation under $660 \mathrm{~nm}$ light irradiation. Taking advantage of these Ir-NPs, cellular imaging in the far-red range was realized; meanwhile, in vitro PDT was successfully performed. These results suggested that the Ir-NPs can function as both bio-imaging agents and nano-photosensitizers that work in the far red range.
\end{abstract}

Keywords: Iridium (III) complex; Fluorescence imaging; Nanoparticles; Photodynamic therapy; Oxygen

\section{Introduction}

Fluorescence imaging has become a highly sensitive and indispensable technique for noninvasive visualization of living specimens with subcellular resolution that cannot be achieved by ultrasound or magnetic resonance imaging [1-3]. In particular, fluorescence imaging with long wavelength ranged from far-red to near-infrared (NIR) (650-900 nm) is much desired for in vivo imaging and medical diagnosis because of the merits of minimal interference from tissue autofluorescence, reduced light scattering, and high tissue penetration [4-6]. To date, various such imaging agents have been developed, including organic dyes [7], lanthanide upconversion nanoparticles (NPs) [8], fluorescent quantum dots [9], phosphorescent transition-metal complexes [10], etc. However, novel long-wavelength probes with high stability, biocompatibility and luminescent efficiency are still badly needed $[11,12]$.

Phosphorescent iridium (III) complexes are traditionally used as organic light-emitting diodes (OLED) materials [13-15]. Recently, cyclometalated 
iridium complexes with NIR emissions have attracted great attention as bio-imaging agents [16, 17]. The strong spin-orbit coupling caused by heavy atom iridium enables highly efficient emission from metal-to-ligand charge transfer transition (MLCT) states, whilst the large stokes shift helps to reduce the influence of excitation light. Unfortunately, phosphorescent of iridium complex is severely quenched by oxygen because of energy transfer from long-lived triplet MLCT state to triplet ground state of oxygen molecules. In this respect, iridium complexes are ideal phosphorescent oxygen probes [18-20], and have been widely utilized to sense cellular oxygen or to image tumor hypoxia [21, 22]. More recently, NIR phosphorescent iridium complexes have expanded their application as photodynamic therapy (PDT) agents [23-25]. Under light illumination, the interaction between molecular oxygen and excited MLCT states generates reactive singlet oxygen $\left({ }^{1} \mathrm{O}_{2}\right)$, which leads to cell death and tissue destruction. These iridium complexes are either grafted with water-soluble groups [26] or embedded into hydrophilic NPs [27] to be compatible with biological environments, since most of them are hydrophobic. In terms of bio-imaging agents, however, the oxygen-dependent phosphorescence is disadvantageous as biological environments are rich with oxygen. Few attempts have been made to address this issue up to now, except for the synthesis of caged iridium complexes wherein phosphorescence was shielded from oxygen quenching to some degree [28].

In this work, a far-red phosphorescent hydrophobic iridium complex with emission wavelength at 668 nm was embedded into biocompatible NPs using a modified encapsulation-reprecipitation method [3, 29-31]. Phosphorescence of the complex was highly oxygen-sensitive in organic solvent, but became nearly independent of oxygen after being immobilized into particle matrix that was actually oxygen-permeable. More interestingly, the iridium complex-based NPs exhibited high photocytotoxcity after illumination with red light. Taking advantage of the dual-functional NPs, in vitro PDT experiments were performed with a $660 \mathrm{~nm}$ laser, and morphology of the cells was simultaneously monitored with a confocal microscopy.

\section{Materials and Methods}

\section{Materials}

Bis(2,3-diphenylquinoxaline-C2,N)(acetylacetonate) iridium(III) ((DPQ) $)_{2} \operatorname{Ir}($ acac $)$ ) was obtained from
Beijing Beidaoled Technology Co. Ltd (China), dodecyltrimethoxysilane (DTS) was from Jiaxing Sicheng Chemicals Co. Ltd (China), THF from J\&K(China). Poly-L-lysine (PLL, $M_{\mathrm{w}}=30-70 \mathrm{kDa}$ ) and Polystyrene (PS, $M_{\mathrm{w}}=280 \mathrm{kDa}$ ) were purchased from Sigma-Aldrich. All chemicals were used without further purification. Deionized water (DI) was used in all experiments.

\section{Methods}

\section{Characterization}

UV-vis absorption and steady-state photoluminescent spectra were recorded on a UV-3101PC spectrophotometer (Shimadzu) and an F-4600 fluorescence spectrophotometer (Hitachi), respectively. SEM images were performed on a field emission scanning electron microscope (JEOL JSM-7500F), using aqueous dispersion of NPs placed on the SEM specimen support (aluminum), subsequently evaporated at room temperature and sputter coated with Au. Hydrodynamic sizes were determined by dynamic light scattering (DLS) with a Zetasizer Nano instrument (Malvern Instruments; www.malvern.com). The measurements were performed at $25^{\circ} \mathrm{C}$ with a detection angle of $90^{\circ} \mathrm{C}$.

\section{Preparation of (DPQ) $)_{2} \operatorname{Ir}(\mathrm{acac})$-doped NPs (Ir- NPs)}

In a typical experiment, (DPQ) $)_{2} \operatorname{Ir}(\mathrm{acac}), \mathrm{PS}$, and DTS were dissolved in THF, in a 10:40:50 weight ratio, with a total concentration of $500 \mathrm{ppm}$. Then, 500 $\mu \mathrm{L}$ of stock solution was rapidly injected into $8 \mathrm{~mL}$ of water containing $0.16 \mathrm{mg}$ PLL $(\mathrm{pH}=9$, adjusted by ammonium hydroxide) under sonication. The resulting suspensions were left for $2 \mathrm{~h}$, and further dialyzed against distilled water for $24 \mathrm{~h}$ to remove organic solvent. The resulting suspensions (containing around $60 \mathrm{mg}$ of NPs per liter) were stored at $4{ }^{\circ} \mathrm{C}$ for further experiments.

\section{Oxygen sensitivity of phosphorescent Ir-NPs}

Oxygen sensitivity of phosphorescence of $(\mathrm{DPQ})_{2} \operatorname{Ir}(\mathrm{acac})$ in THF and NPs was carried out in a cell that was sealed with parafilm (Chicago, IL, USA), through which two 1.5-in. needles were inserted as gas inlet and outlet ports. Different dissolved oxygen (DO) concentrations were obtained by flowing an oxygensaturated (99.6\%) or nitrogen-saturated $(99.6 \%)$ gas for 10 minutes respectively. All spectral measurements were performed at room temperature. 


\section{Determination of singlet oxygen generation}

Experiments to detect singlet oxygen were performed by measuring the absorption of a chemical probe, 3-diphenylisobenzofuran (DPBF) [32]. Typically, 20 $\mathrm{mL}$ DPBF (1000 ppm in DMSO) were added to $2 \mathrm{~mL}$ of iridium-doped NPs aqueous dispersion in a quartz cuvette. The cuvette was kept in the dark and irradiated with a $660 \mathrm{~nm}$ continuous wave laser (CW laser) for $20 \mathrm{~min}$, and the absorption spectrum was recorded at intervals. The rate of singlet oxygen production was determined from the reduction of DPBF absorbance over time. Irradiation of DPBF with the absence of Irloaded NPs was also carried out as a negative control.

\section{Cell culture and cytotoxicity of Ir-NPs}

HepG2 (human hepatocellular liver carcinoma cell line) were used for the cellular studies in the experiment. The cells were cultured in $6 \mathrm{~cm}$ culture dishes with $4 \mathrm{~mL} \mathrm{H-DMEM} \mathrm{medium} \mathrm{containing} \mathrm{10 \%}$ FBS and incubated at $37^{\circ} \mathrm{C}$ in a $5 \% \mathrm{CO}_{2}$ environment. During the culturing of cells, fresh medium was replaced every 2 days.

Cytotoxicity of Ir-NPs was determined with a MTT assay. Briefly, HepG2 cells were seeded into a 96-well microtiter plate with $5 \times 10^{3}$ cells per well and cultured at $37{ }^{\circ} \mathrm{C}$ for $24 \mathrm{~h}$. NPs solutions at different concentrations (0, 9.6, 19.2, 28.8, 38.4, $48 \mu \mathrm{g} \mathrm{mL}^{-1}$ ) were added into the wells, respectively. The cells were further cultured at $37^{\circ} \mathrm{C}$ for $24 \mathrm{~h}$ and then $20 \mu \mathrm{L}$ 3-(4, 5-dimethylthiazol-2-yl)-2, 5-diphenyltetrazolium bromide (MTT, $5 \mathrm{mg} \mathrm{mL}^{-1}$ in PBS solution, $\mathrm{pH}$ 7.4) solution was added into each well. After being cultured for $4 \mathrm{~h}$, the mixed solution was dumped off and formazan (MTT metabolic product) was dissolved by adding $100 \mu \mathrm{L} /$ well dimethyl sulfoxide (DMSO). The absorbance of the solution was measured at $490 \mathrm{~nm}$ with an ELISA reader (BioTek, ELx800TM). The relative cell viability (\%) related to control wells containing cell culture medium without NPs was calculated by OD (test)/OD (control) $\times 100$.

\section{Intracellular uptake imaged by confocal microscopy}

HepG2 cells were cultured for $24 \mathrm{~h}$ in $35 \mathrm{~mm}$ confocal culture dishes to reach a density of $1 \times 10^{5}$ cells per dish. Then, $0.5 \mathrm{~mL}$ of Ir-NPs suspension and $1.5 \mathrm{~mL}$ of H-DMEM medium were co-added into the culture dishes, followed by $12 \mathrm{~h}$ incubation to load these NPs into cells. After incubation, the cells were washed three times with PBS before microscopy viewing. Intracellular imaging was conducted on an
Olympus FV1000 confocal laser scanning microscope (www.olympus.com). Acquisition of each spectral signal was done in Kalman laser mode. The NPs were excited at $488 \mathrm{~nm}$ with emission collected at 650 700 nm.

\section{In vitro PDT characterized by MTT and confocal microscopy}

HepG2 cells were grown in a 96-well plates at $5 \times 10^{3}$ per well and then incubated for $24 \mathrm{~h}$ at $37^{\circ} \mathrm{C}$ under $5 \%$ $\mathrm{CO}_{2}$. Ir-NPs aqueous suspension was added into each well with a concentration of $28.8 \mu \mathrm{g} \mathrm{mL}^{-1}$, and the total volume was kept at $200 \mu \mathrm{L}$. After being incubated for $24 \mathrm{~h}$, the cells were rinsed twice with PBS before exposure to light irradiation. For the control experiment without light irradiation, another 96-well plate was needed. A $660 \mathrm{~nm}$ CW laser was employed to irradiate the 96-well plate with an output power density of $\sim 100 \mathrm{~mW} \mathrm{~cm}^{-2}$ for $20 \mathrm{~min}$. The PDT-treated cells were further incubated for $24 \mathrm{~h}$, and cell viability was assayed with the standard MTT assay described previously.

For confocal observation of PDT-treated cells, procedures of cell culture in confocal culture dishes, cell incubation with Ir-NPs, and light irradiation with $660 \mathrm{~nm}$ light are the same as previously described. Afterwards, the PDT-treated cells were further cultured for $24 \mathrm{~h}$. Before microscopy viewing, the cells were either stained by calcein-AM (CAM, $2.5 \mu \mathrm{M}$ ) or propidium iodide (PI, $5 \mu \mathrm{g} \mathrm{mL}^{-1}$ ) for $10 \mathrm{~min}$ to respectively discriminate alive or dead cells, followed by washing with PBS for three times. Intracellular imaging was conducted on an Olympus FV1000 confocal laser scanning microscope. Acquisition of each spectral signal was done in Kalman laser mode.

\section{Results and Discussion \\ Synthesis and characterization of phosphore- scent Ir-NPs}

(DPQ) 2 Ir(acac)-doped biocompatible NPs (Ir-NPs) were prepared by previously reported encapsulationreprecipitation method [3]. Briefly, the hydrophobic species of PS, DTS and DPQ) ${ }_{2} \operatorname{Ir}$ (acac) aggregated into nanoparticles under hydrophobic interaction after being injected into water, which were subsequently encapsulated by a PLL shell. Figure 1(a) shows SEM image of resultant PLL-coated NPs, which are almost spherical with an average diameter of $110 \mathrm{~nm}$ (inset to the figure). Hydrodynamic size of Ir-NPs is determined to be $130 \mathrm{~nm}$ by DLS (Fig. 1(b)), which is a little 
(a)

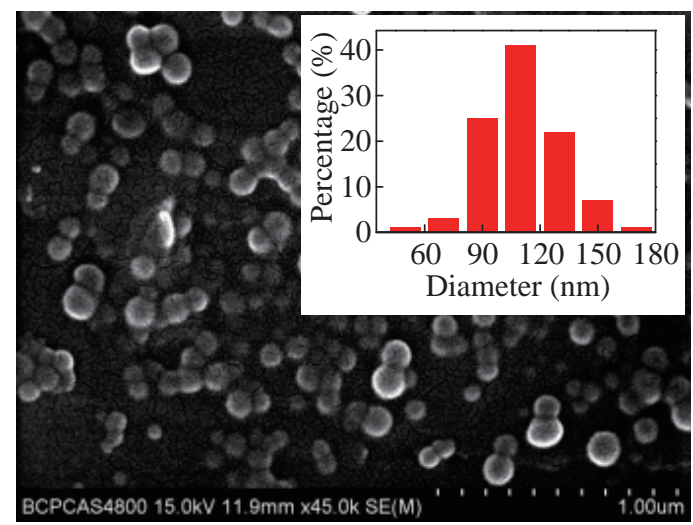

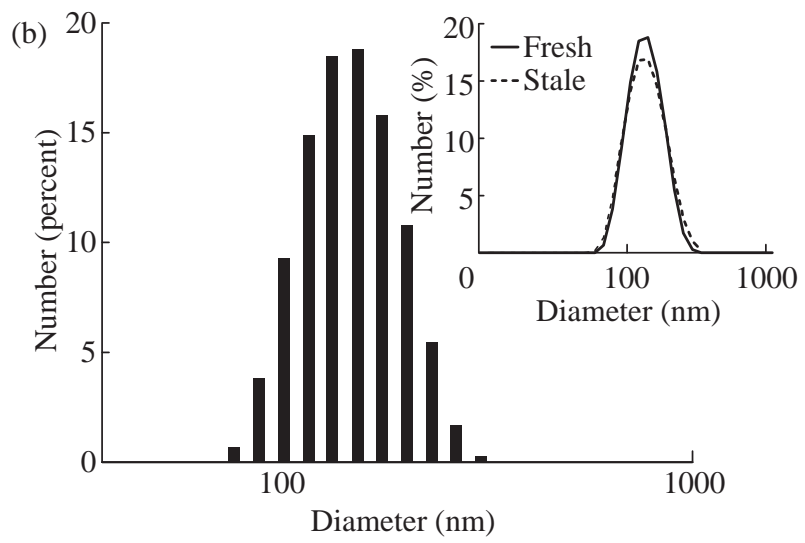

Fig. 1 (a) SEM image with inset of particle size distribution; (b) DLS analysis of (DPQ) 2 Ir(acac)-doped NPs. Inset to (b) shows DLS data of respective Ir-NPs in solution, fresh (solid line) versus stale (after two-month storage, dotted line).

bigger than in dry state as amine groups on PLL layer stretch out in aqueous solution. The PLL-coated NPs are rather stable in water, with neglectable size broadening after being kept for two months (determined by DLS, Fig. 1(b)).

In Ir-NPs, (DPQ) $)_{2} \operatorname{Ir}(\mathrm{acac})$ molecules are randomly distributed inside the hybrid particle matrix consisting of PS and DTS. Figure 2 shows spectral properties of (DPQ) ${ }_{2} \operatorname{Ir}($ acac) before (in THF) and after incorporation into NPs. It can be seen that the spectra of iridium complexes in NPs are similar to that in THF. The three absorption bands at $283 \mathrm{~nm}, 381$ $\mathrm{nm}$ and $480 \mathrm{~nm}$ are assigned to spin-allowed $\pi-\pi^{*}$ transition of DPQ ligand, spin-allowed ${ }^{1}$ MLCT band and spin-forbidden ${ }^{3} \mathrm{MLCT}$, respectively, and the far red emission at around $668 \mathrm{~nm}$ is from ${ }^{3}$ MLCT [13]. Ir-NPs with different concentrations of (DPQ $)_{2} \operatorname{Ir}(\mathrm{acac})$ were prepared, and the doping ratio of $10 \mathrm{wt} . \%$ gave rise to highest intensive phosphorescence (inset to Fig. 2(b)).

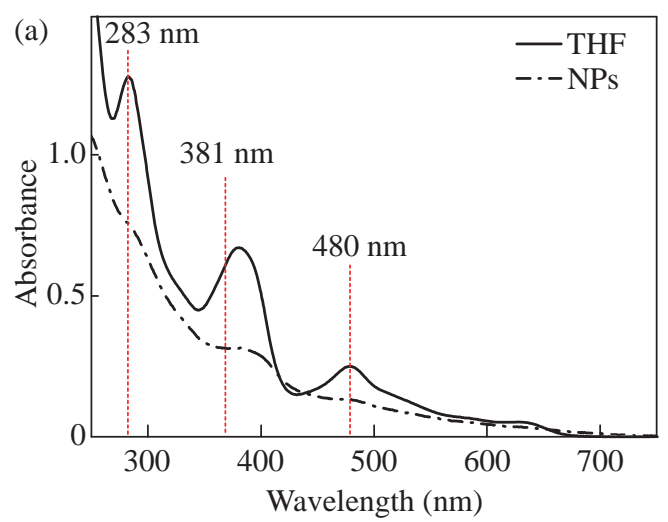

\section{Oxygen sensitivity and intracellular imaging of phosphorescent Ir-NPs}

As noted previously, most phosphorescent iridium complexes are sensitive to oxygen. Figure 3 shows oxygen-dependent emission spectra of the iridium complex in THF and NPs. It can be seen clearly that the $668 \mathrm{~nm}$ far-red emission of (DPQ) $)_{2} \operatorname{Ir}(\mathrm{acac})$ is greatly quenched by oxygen in THF, but is less influenced in NPs. Oxygen sensitivity can be expressed by the overall quenching response to oxygen [30], $Q=$ $\left(I_{\mathrm{N} 2}-I_{\mathrm{O} 2}\right) / I_{\mathrm{N} 2}$, where $I_{\mathrm{N} 2}$ and $I_{\mathrm{O} 2}$ represent the emission intensity of (DPQ) ${ }_{2} \operatorname{Ir}(\mathrm{acac})$ in fully deoxygenated and fully oxygenated solutions, respectively. The as-obtained value of $Q$ is about $94 \%$ and $26 \%$, respectively, for THF and NPs. It is obviously that oxygen sensitivity of (DPQ) $\operatorname{Ir}$ (acac) is considerably decreased in Ir-NPs, which thus enable them to be qualified bio-imaging agents. It needs to point out that the PS-DTS hybrid matrix of Ir-NPs is highly oxygenpermeable, and other phosphorescent metal complexes

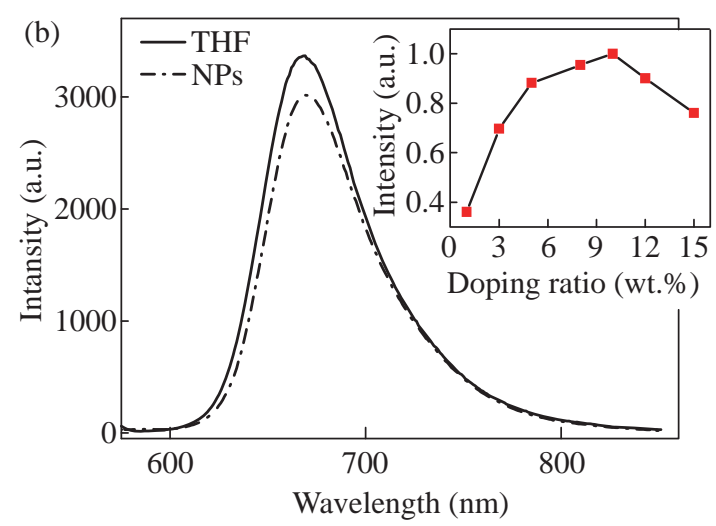

Fig. 2 Spectral properties of (DPQ) $)_{2}$ Ir(acac) in THF and NPs: (a) Absorption spectra; (b) Emission spectra with a $488 \mathrm{~nm}$ excitation. Concentration of (DPQ) $)_{2} \mathrm{Ir}(\mathrm{acac})$ in THF and NPs is $5 \mathrm{ppm}$ and $10 \mathrm{wt}$ \%, respectively. Inset to (b) is the phosphorescence intensity (668 nm) of Ir-NPs versus concentration of doped complex. 

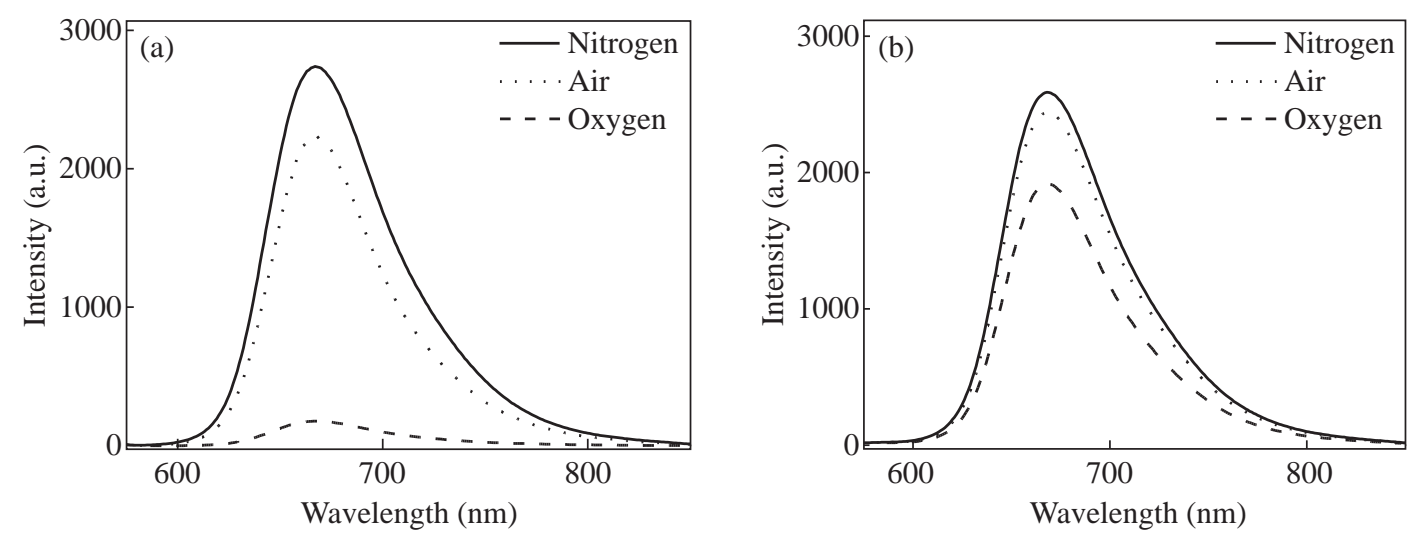

Fig. 3 Emission spectra of (DPQ) $2 \operatorname{Ir}(\mathrm{acac})$ in (a) THF and (b) NPs saturated with nitrogen (solid), air (dot) and oxygen (dash), respectively. The excitation wavelength is at $488 \mathrm{~nm}$.

(e.g. PdOEP and PtTFPP) have been doped into the same particle matrix to prepare highly sensitive oxygen nanosensors [29, 31]. The mechanism of insensitivity of Ir-NPs against oxygen is not clear presently, and further work is needed.

Cytotoxicity of Ir-NPs was investigated on living human hepatocellular liver carcinoma (HepG2) cells by MTT assay. The results are listed in Fig. 4(a), showing that a loading capacity below $28.8 \mu \mathrm{g} \mathrm{mL}^{-1}$ gives rise to relatively lower inhibition of cells. Cellular uptake of the NPs was then evaluated by confocal laser scanning microscopy and intensive red phosphorescence in cells was observed under a $488 \mathrm{~nm}$ excitation (Fig. 4(b)). The overlay of bright field and luminescence images confirms that the NPs are mainly located inside cytoplasm without obvious nuclear uptake. These data demonstrate that Ir-NPs are very promising far-red phosphorescent biomarker.

\section{Singlet oxygen generation and in vitro photodynamic therapy}

It can be observed from Fig. 2(a) that the absorption band of Ir-NPs is extends up to $660 \mathrm{~nm}$. PDT experiment was then tentatively performed with
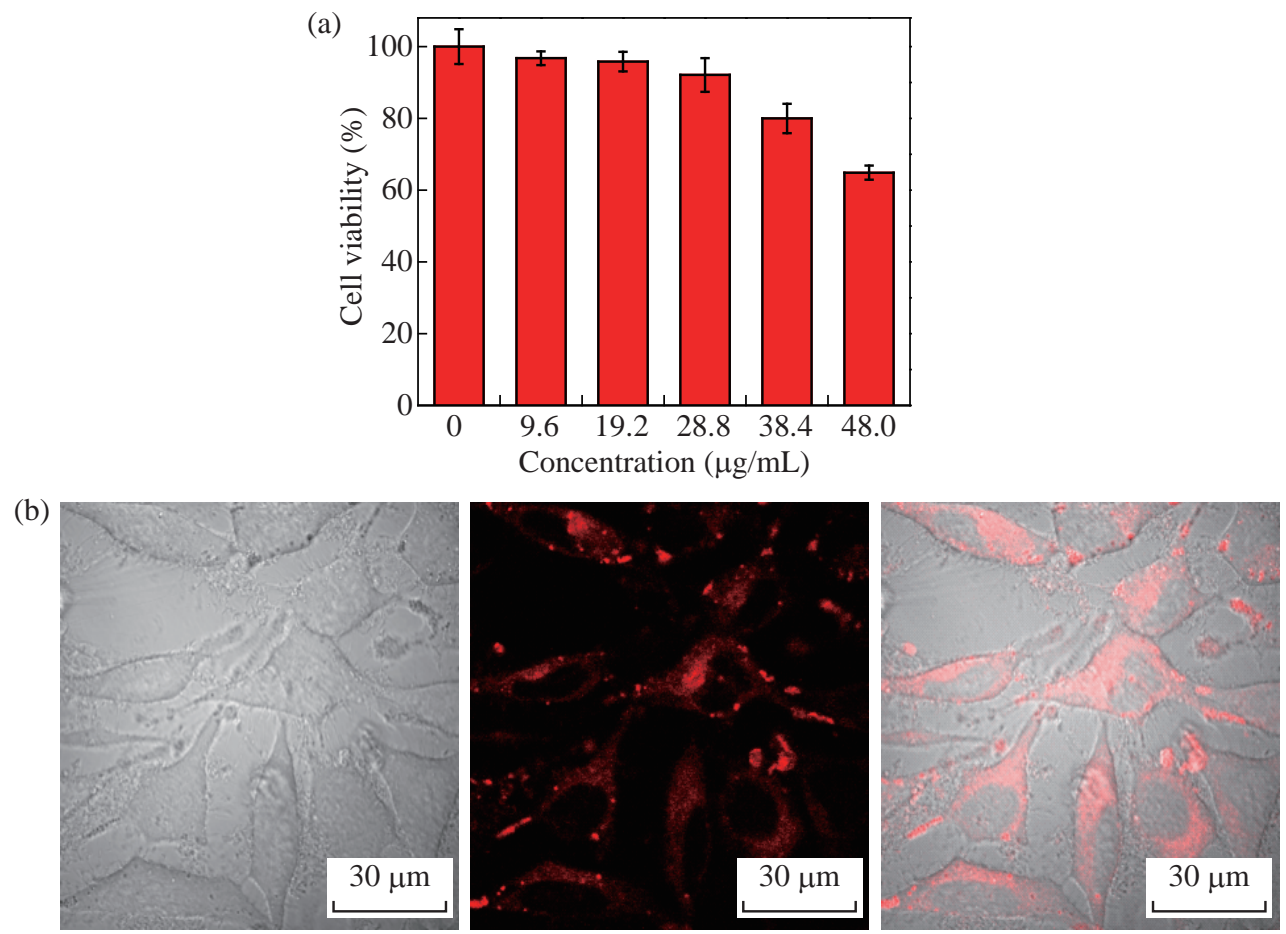

Fig. 4 (a) Viability of HepG2 cells assessed by MTT assay after incubation with different amounts of Ir-NPs; (b) Bright field (left), confocal (middle), and overlay (right) images of HepG2 cells loaded with $28.8 \mu \mathrm{g} \mathrm{mL}^{-1} \mathrm{NPs}$. The red fluorescence was collected at 650-700 nm under a $488 \mathrm{~nm}$ excitation (scale bar: $30 \mu \mathrm{m}$ ). 
a $660 \mathrm{~nm}$ light, and the singlet oxygen generation efficiency of Ir-NPs was evaluated by using 1,3-diphenylisobenzofyran (DPBF) assay. As shown in Fig. 5(a), the absorption intensity of DPBF at $410 \mathrm{~nm}$ decreases gradually with irradiation time, indicating fast generation of ${ }^{1} \mathrm{O}_{2}$ from NPs. Obviously, Ir-NPs can be used as nano-photosensitizers under the irradiation of far red light. The ability to produce ${ }^{1} \mathrm{O}_{2}$ also confirms the above assumption that oxygen-insensitivity of IrNPs is not due to block of oxygen by particle matrix.
As a matter of fact, we have utilized the same particle matrix to prepare zinc (II) phthalocyanine-doped nanophotosensitizers [33]. Fig. 5(b) compares the rate of degradation of DPBF by Ir-NPs with different doping ratios. The optimal loading capacity of (DPQ $)_{2} \operatorname{Ir}(\mathrm{acac})$ is determined to be $10 \%$, which is consistent with the result of phosphorescent intensity. For 10\%-doped Ir-NPs, moreover, nearly $75 \%$ of the DPBF was consumed after 5 min irradiation, which is very efficient compared with other Ir-complex based nano-
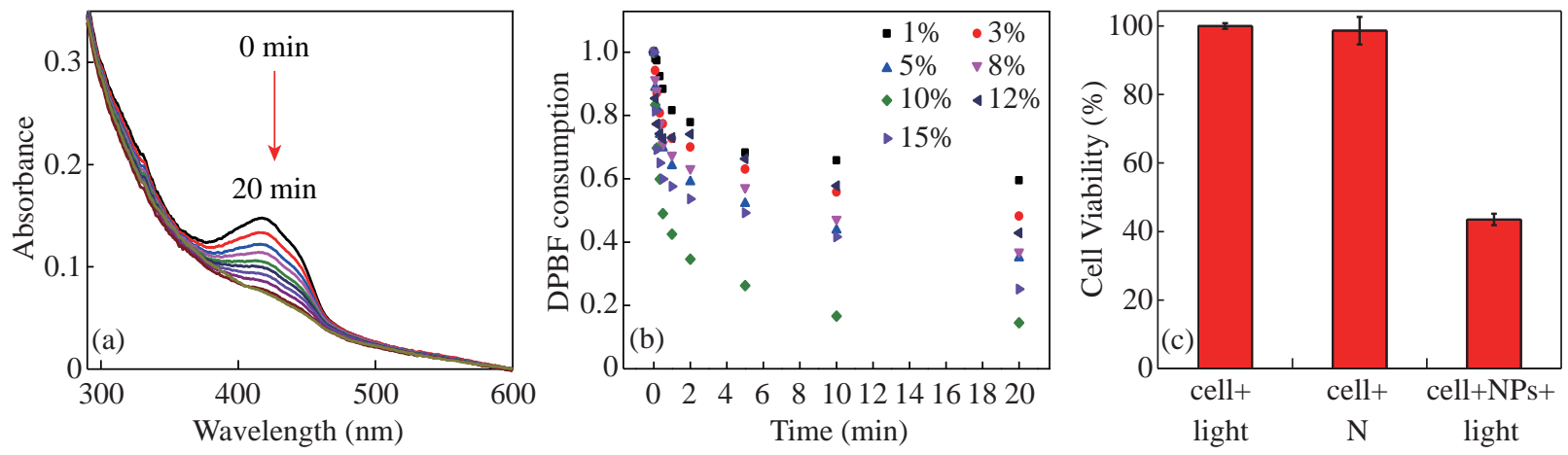

Fig. 5 (a) UV/Vis absorption spectra of a mixture of DPBF (10 ppm) with Ir-NPs (10\%) aqueous solution under $660 \mathrm{~nm}$ irradiation for 0, 5, 10, 20, 30, 60, 120, 300, 600, and 1200 s respectively; (b) Consumption of DPBF over time for Ir-NPs doped with different concentration of (DPQ) $)_{2} \operatorname{Ir}(\mathrm{acac})$; and (c) Viability of HepG2 cells treated with Ir-NPs with or without $660 \mathrm{~nm}$ irradiation. As the control group, cells without NPs are similarly irradiated with light.
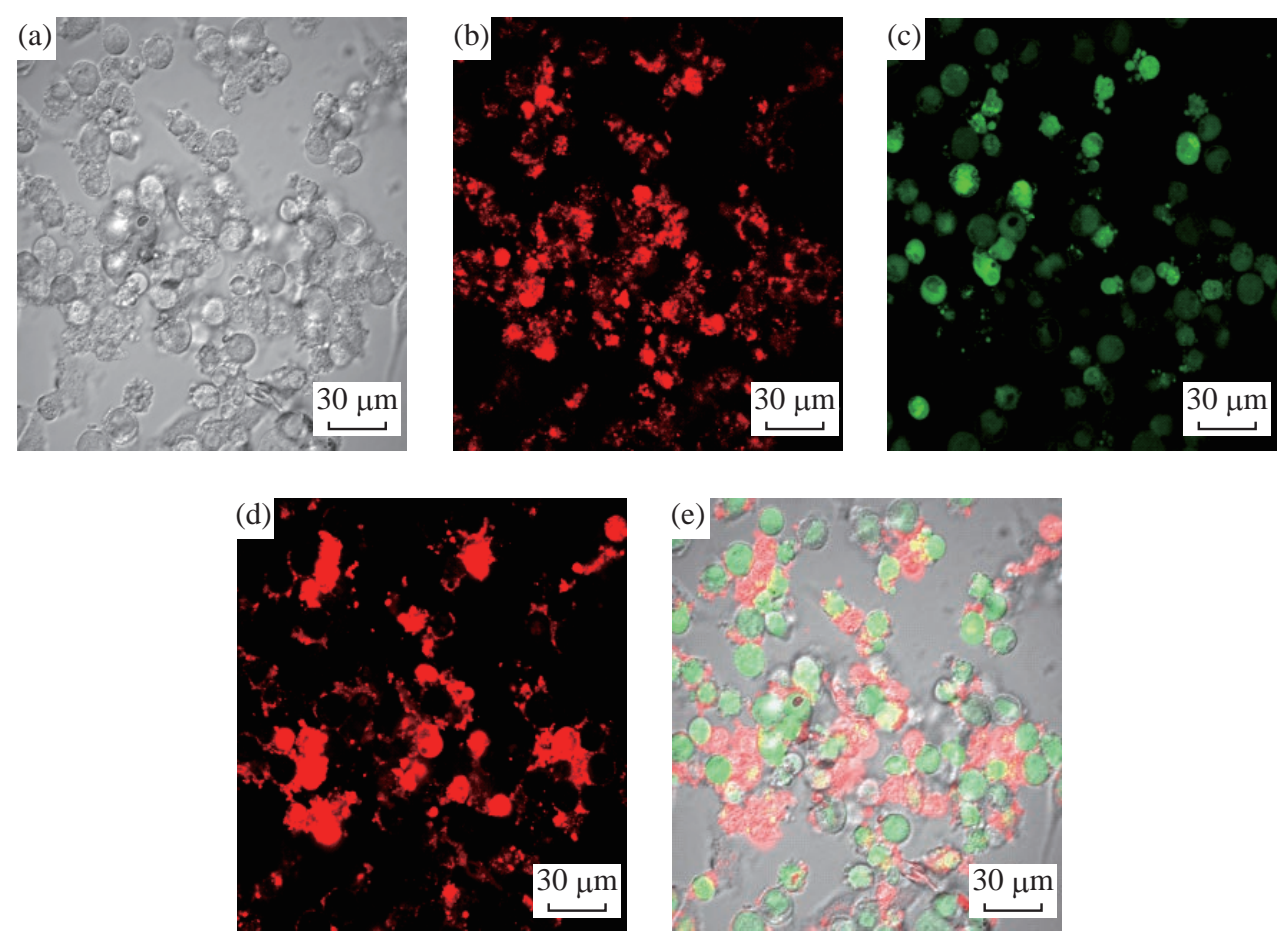

Fig. 6. (a) Bright field image and confocal fluorescence images of PDT-treated HepG2 cells loaded with Ir-NPs: (b) phosphorescence from Ir-NPs $\left(\lambda_{\text {ex }}=488 \mathrm{~nm}\right.$, collected at 650-700 nm); (c) further stained with calcein AM $\left(\lambda_{\text {ex }}=488 \mathrm{~nm}\right.$, collected at 500-550 nm) and with (d) propidium iodide $\left(\lambda_{\mathrm{ex}}=539 \mathrm{~nm}\right.$, collected at 580-630 nm) respectively; and (e) overlay image of (a), (c) and (d). (Scale bar: $30 \mu \mathrm{m})$. 
photosensitizers, e.g. Ir-PPy NPs wherein it took more than one hour to consume similar percentage of DPBF [23].

After incubation with Ir-NPs, in vitro PDT was then performed on HepG2 cells under the illumination of a $660 \mathrm{~nm}$ light. Figure 5(c) shows phototoxicity of Ir-NPs assessed by MTT assay. The photothermal effect induced by $660 \mathrm{~nm}$ laser on cell viability was checked in advance. It is found that 20 min's irradiation renders negligible effect on cell viability. With the presence of Ir-NPs, a significant decrease in cell viability is observed, indicating that a small dose of nano-photosensitizers $\left(28.8 \mu \mathrm{g} \mathrm{mL}^{-1}\right)$ can cause serious phototoxicity. The in vitro PDT efficacy of IrNPs was further checked by confocal laser scanning microscopy (Fig. 6). It can be seen that the residue of PDT-treated cells could be still imaged according to the far-red phosphorescent Ir-NPs (Fig. 6(b)). As for their viability, some are alive (green channel labeled with calcein AM, Fig. 6(c)), and some are dead (red channel labeled with propidium iodide, Fig. 6(d)). The result is approximately consistent with that assessed by MTT assay (about 40\% viability).

\section{Conclusions}

In summary, a dual-functional nanoparticle doped with (DPQ) $)_{2} \operatorname{Ir}(\mathrm{acac})$ was prepared for far red phosphorescence imaging and PDT therapy of living cells. The $668 \mathrm{~nm}$ emission of iridium complex was highly sensitive to oxygen in organic solvent, but became less insensitive after being immobilized by PSDTS particle matrix. Moreover, Ir-NPs exhibited a fast rate of singlet oxygen generation under $660 \mathrm{~nm}$ light irradiation. The as-prepared NPs were effectively taken up by HepG2 cells due to the high biocompatibility of PLL layer and small size ( $\sim 10 \mathrm{~nm}$ in diameter). Based on the optimized Ir-NPs (10\% doping ratio), HepG2 cells were not only optically imaged in the range of 650-700 nm, but also were damaged by PDT therapy of 660-nm illumination. These results demonstrated that the Ir-NPs are strong candidates for both bio-imaging agents and nano-photosensitizers that work with farred wavelength.

\section{Acknowledgements}

This work was financially supported by the NSFC (Grants 61575017 and 11274038) and the NCET (12-0771).

\section{References}

[1] D.J. Stephens, Light Microscopy Techniques for Live Cell Imaging. Science, 2003, 300(5616): 82-86.

[2] T. Ueno, T. Nagano, Fluorescent probes for sensing and imaging. Nat Methods, 2011, 8(8): 642-645.

[3] H.S. Peng, D.T. Chiu, Soft fluorescent nanomaterials for biological and biomedical imaging. Chem Soc Rev, 2015, 44(14):4699-4722.

[4] V. Pansare, S. Hejazi, W. Faenza, et al., Review of LongWavelength Optical and NIR Imaging Materials: Contrast Agents, Fluorophores and Multifunctional Nano Carriers. Chem Mater, 2012, 24(5): 812-827.

[5] Z. Guo, S. Park, J. Yoon, et al., Recent progress in the development of near-infrared fluorescent probes for bioimaging applications. Chem Soc Rev, 2014, 43(1): 1629.

[6] S.A. Hilderbrand, R. Weissleder, Near-infrared fluorescence: application to in vivo molecular imaging. Curr Opin Chem Biol, 2010, 14(1): 71-79.

[7] S. Luo, E. Zhang, Y. Su, et al., A review of NIR dyes in cancer targeting and imaging. Biomaterials, 2011, 32(29): 7127-7138.

[8] Y. Dai, H. Xiao, J. Liu, et al., In vivo multimodality imaging and cancer therapy by near-infrared lighttriggeredtrans-platinum pro-drug-conjugated upconverison nanoparticles. J Am Chem Soc, 2013, 135(50): 18920-18929.

[9] S.Y. Kuo, H.H. Li, P.J. Wu, et al., Dual colorimetric and fluorescent sensor based on semiconducting polymer dots for ratiometric detection of lead ions in living cells. Anal Chem, 2015, 87(9): 4765-4771.

[10] M. Hu, J. Zhao, X. Ai, et al., Near infrared light-mediated photoactivation of cytotoxic Re(i) complexes by using lanthanide-doped upconversion nanoparticles. Dalton Trans., 2016, 45(36): 14101-14108.

[11] Z.Q. Chen, Z.Q. Bian, and C.H. Huang, Functional IrIII complexes and their applications. Adv Mater, 2010, 22(13): 1534-1539.

[12] X. Yi, F. Wang, W. Qin, et al., Near-infrared fluorescent probes in cancer imaging and therapy: an emerging field. Int J Nanomedicine, 2014, 9: 1347-1365.

[13] G.L. Zhang, Z.H. Liu, and H.Q. Guo, Synthesis and photoluminescence of a new red phosphorescent iridium(iii) quinoxaline complex. Chinese Chem Lett, 2004, 15(11): 1349-1352.

[14] J. Park, J.S. Park, Y.G. Park, et al., Synthesis, characterization of the phenylquinoline-based on iridium(III) complexes for solution processable phosphorescent organic light-emitting diodes. Org Electron, 2013, 14(9): 2114-2123.

[15] M. Song, S.J. Yun, K.S. Nam, et al., Highly efficient solution-processed pure red phosphorescent organic light-emitting diodes using iridium complexes based on 2,3-diphenylquinoxaline ligand. J Organomet Chem, 2015, 794: 197-205.

[16] Y. Chen, L. Qiao, L. Ji, et al., Phosphorescent iridium(III) complexes as multicolor probes for specific mitochondrial imaging and tracking. Biomaterials, 2014, 35(1): 2-13.

[17] G. Zhang, H. Zhang, Y. Gao, et al., Near-infrared-emitting iridium(III) complexes as phosphorescent dyes for live cell imaging. Organometallics, 2014. 33(1): 61-68.

[18] G. Di Marco, M. Lanza, M. Pieruccini, et al., A luminescent iridium(III) cyclometallated complex immobilizedin a polymericmatrix as a solid-state oxygen sensor. Adv Mater, 1996, 8(7): 576-580.

[19] S. Medina-Rodriguez, S.A. Denisov, Y. Cudre, et al., High performance optical oxygen sensors based on iridium complexes exhibiting interchromophore energy shuttling. Analyst, 2016, 141(10): 3090-3097. 
[20] X.D. Wang, O.S. Wolfbeis, Optical methods for sensing and imaging oxygen: materials, spectroscopies and applications. Chem Soc Rev, 2014, 43(10): 3666-3761.

[21] T. Yoshihara, S. Murayama, and S. Tobita, Ratiometric molecular probes based on dual emission of a blue fluorescent coumarin and a red phosphorescent cationic iridium(III) complex for intracellular oxygen sensing. Sensors (Basel), 2015, 15(6): 13503-13521.

[22] X. Zheng, H. Tang, C. Xie, et al., Tracking cancer metastasis in vivo by using an iridium-based hypoxiaactivated optical oxygen nanosensor. Angew Chem Int Ed Engl, 2015, 54(28): 8094-8099.

[23] F. Xue, M. Shi, Y. Yan, et al., Iridium complex loaded polypyrrole nanoparticles for NIR laser induced photothermal effect and generation of singlet oxygen. RSC Adv., 2016, 6(19): 15509-15512.

[24] F. Xue, Y. Lu, Z. Zhou, et al., Two in one: Luminescence imaging and $730 \mathrm{~nm}$ continuous wave laser driven photodynamic therapy of iridium complexes. Organometallics, 2015, 34(1): 73-77.

[25] P. Majumdar, X. Yuan, S. Li, et al., Cyclometalated Ir(iii) complexes with styryl-BODIPY ligands showing near IR absorption/emission: preparation, study of photophysical properties and application as photodynamic/luminescence imaging materials. J Mater Chem B, 2014, 2(19): 28382854.

[26] P. Steunenberg, A. Ruggi, N.S. van den Berg, et al., Phosphorescence imaging of living cells with amino acid-functionalized tris(2-phenylpyridine)iridium(III) complexes. Inorg Chem, 2012, 51(4): 2105-2114.

[27] J. Zhang, R. Chen, Z. Zhu, et al., Highly stable nearinfrared fluorescent organic nanoparticles with a large stokes shift for noninvasive long-term cellular imaging.
ACS Appl Mater Interfaces, 2015, 7(47): 26266-26274.

[28] A. Ruggi, M. Berenguel Alonso, D.N. Reinhoudt, et al., An iridium(III)-caged complex with low oxygen quenching. Chem Commun (Camb), 2010, 46(36): 67266728.

[29] X.H. Wang, H.S. Peng, H. Ding, et al., Biocompatible fluorescent core-shell nanoparticles for ratiometric oxygen sensing. J Mate Chem, 2012, 22(31): 1606616071.

[30] X.H. Wang, H.S. Peng, Z. Chang, et al., Synthesis of ratiometric fluorescent nanoparticles for sensing oxygen. Microchimica Acta, 2012, 178(1-2): 147-152.

[31] X.H. Wang, H.S. Peng, L. Yang, et al., Targetable phosphorescent oxygen nanosensors for the assessment of tumor mitochondrial dysfunction by monitoring the respiratory activity. Angew Chem Int Ed Engl, 2014, 53(46): 12471-12475.

[32] C. Tanielian, C. Schweitzer, R. Mechin, et al., Quntum yield of singlet oxygen production by monomeric and aggregated forms of hematoporphyrin derivative. Free Radical Bio Med, 2001, 30(2): 208-212.

[33] J.T. Ping, H.S. Peng, W.B. Duan, et al., Synthesis and optimization of ZnPc-loaded biocompatible nanoparticles for efficient photodynamic therapy. J. Mater. Chem. B, 2016, 4(25): 4482-4489.

Copyright $₫ 2017$ Lanying Guo, Hongshang Peng, Ruiying Shen, Jiantao Ping, Fangtian You, Yiquan Wang, Min Song, and Qu Zhen. This is an open-access article distributed under the terms of the Creative Commons Attribution License, which permits unrestricted use, distribution, and reproduction in any medium, provided the original author and source are credited. 